\title{
Expression Patterns of Cancer Stem Cell Markers During Specific Celecoxib Therapy in Multistep Rat Colon Carcinogenesis Bioassays
}

\author{
Elsayed I Salim ${ }^{1 *}$, Mona M Hegazi ${ }^{1}$, Jin Seok Kang ${ }^{2}$, Hager M Helmy ${ }^{1}$
}

\begin{abstract}
The purpose of this study was to investigate the role of colon cancer stem cells (CSCs) during chemicallyinduced rat multi-step colon carcinogenesis with or without the treatment with a specific cyclooxygenase-2 inhibitor drug (celecoxib). Two experiments were performed, the first, a short term 12 week colon carcinogenesis bioassay in which only surrogate markers for colon cancer, aberrant crypt foci (ACF) lesions, were formed. The other experiment was a medium term colon cancer rat assay in which tumors had developed after 32 weeks. Treatment with celecoxib lowered the numbers of ACF, as well as the tumor volumes and multiplicities after 32 weeks. Immunohistochemical proliferating cell nuclear antigen (PCNA) labeling indexes LI (\%) were downregulated after treatment by celecoxib. Also different cell surface antigens known to associate with CSCs such as the epithelial cell adhesion molecule (EpCAM), CD44 and CD133 were compared between the two experiments and showed differential expression patterns depending on the stage of carcinogenesis and treatment with celecoxib. Flow cytometric analysis demonstrated that the numbers of CD133 cells were increased in the colonic epithelium after 12 weeks while those of CD44 but not CD133 cells were increased after 32 weeks. Moreover, aldehyde dehydrogenase-1 activity levels in the colonic epithelium (a known CSC marker) detected by ELISA assay were found down-regulated after 12 weeks, but were up-regulated after 32 weeks. The data have also shown that the protective effect of celecoxib on these specific markers and populations of CSCs and on other molecular processes such as apoptosis targeted by this drug may vary depending on the genetic and phenotypic stages of carcinogenesis. Therefore, uncovering these distinction roles of CSCs during different phases of carcinogenesis and during specific treatment could be useful for targeted therapy.
\end{abstract}

Keywords: Colon cancer - rat - cancer stem cells - flow cytometry - ALDH1 - EpCAM - CD44 - CD133 - PCNA

Asian Pac J Cancer Prev, 17 (3), 1023-1035

\section{Introduction}

Cancer stem cells (CSCs) have been recently evidenced in solid tumors from various origins including colon in both human and experimental animals (Wang et al., 2012). Thus a big deal of research has discussed their validity as a new therapeutic target and its role during cancer prognosis (Liu et al., 2015). The prerequisite and challenging step for their identification in tumors is to identify CSCs on the basis of the expression of specific markers and the ability of a very small number of cells to produce a tumor reconstituting the cellular heterogeneity of the original lesion.

Currently, CSCs are recognized by definite surface epitopes. Several stem cell markers have been proposed in human, rat and mouse, that highlight the stem cell or stem cell-like populations in several tissues including breast, colon and pancreas (O'Brien et al., 2007). Most commonly cell surface antigens used as markers for colon cancer cells with CSC-like properties in rodents are CD44, EpCAM, CD133, CD166, Lgr5, etc, depending on the animal species (Vitiani et al., 2007). Dalerba et al., (2007) demonstrated that only a subpopulation of CD44 high/ EpCAM high cells were able to form tumors in xenografts. Also, aldehyde dehydrogenase 1 (ALDH-1) has also been recognized as a promising CSC marker in experimental animals including the rat (Skidan and Steiniger, 2014). Moreover, in the last few years, ALDH+ is being evaluated as a potential novel cancer prognostic marker in human (Marcato et al., 2011).

The epithelial cell adhesion molecule (EpCAM) produced under regulation of EpCAM gene is found covering the membrane that surrounds epithelial cells, where it helps cell adhesion. EpCAM is also involved in cell signaling, migration, proliferation, and differentiation (Yamamoto and Imai, 2015). Additionally, EpCAM has oncogenic potential via its capacity to up-regulate c-myc, e-fabp, and cyclins A \& E (Tutlewska et al., 2013).

${ }^{1}$ Department of Zoology, Faculty of Science, Tanta University, Research Lab. of Molecular Carcinogenesis, Tanta, Egypt, ${ }^{2}$ Department of Biomedical Laboratory of Science, Namseoul University, Seoul, South Korea *For correspondence: elsalem_777@yahoo.com, elsayed.salim@science.tanta.edu.ed 
Since EpCAM is expressed exclusively in epithelia and epithelial-derived neoplasms, EpCAM can be used as diagnostic marker for various cancers. It appears to play a role in tumorigenesis and metastasis of carcinomas, so it can also act as a potential prognostic marker and as a potential target for immunotherapeutic strategies.

CD44, also called (PGP1) is a receptor for the extracellular matrix protein hyaluranon, was first identified as a potential CSC marker for breast cancers (Al-Hajj et al., 2003) and is, like CD133, a transmembrane glycoprotein. Expression of CD44 is also activated by the beta-catenin/ Tcf-4 complex in colon cancer cells (van de Wetering et al., 2002). CD44 expression is confined to the crypt epithelium in nonneoplastic mucosa of Apc+/Apc1638 mice and increases with progression of cancer. CD44 has many variant splice forms, and prior to its identification as a potential colon CSC marker, it had been demonstrated that expression of several CD44 splice variants correlates with colon cancer progression (Kopp et al., 2009).

CD133 molecule (also known as prominin-1) is expressed in a variety of developing and adult tissues as transmembrane glycoprotein. Lineage-tracing studies of adult Prom1+/C-L mice containing the Rosa26-YFP reporter allele showed that Prom $1+$ cells are located at the base of crypts in the small intestine, co-express Lgr5 (Ricci-Vitiani et al., 2007; Barker et al., 2009), generate the entire intestinal epithelium, and are therefore the small intestinal stem cell. Prom1 was reported recently to mark cancer stem cells of human intestinal tumors that arise frequently as a consequence of aberrant wingless (Wnt) signaling (O'Brien et al., 2007). It is known that Prom1 marks stem cells in the adult small intestine that are susceptible to transformation into tumors retaining a fraction of mutant Prom1+ tumor cells (Zhu et al., 2009).

In the recent years, several natural compounds were found have the ability to kill cancer stem cells, such as salinomycin, curcumin, sulforaphane, a novel gemini vitamin D analog (BXL0124) and so on providing a rationale for preclinical and clinical evaluation of these compounds (Ottinger et al., 2012). Practical findings revealed that administration of celecoxib, a specific COX2 inhibitor, significantly reduced multistep colorectal carcinogenesis in experimental animals (Kim et al., 2014), while recent studies on familial adenomatous polyposis (FAP) in humans revealed that celecoxib alone or accompanied with other drugs reduced adenomas after a short term of treatment (Lynch et al., 2015). However, the multistep nature of carcinogenesis provides opportunities for intervention with agents targeted at specific mechanisms involved in the initiation, promotion, and progression stages of cancers (Steinbach et al., 2000).

On the other hand, since some of the CSC markers such as EpCAM are mainly epithelial cell adhesion molecules, and celecoxib was shown previously to reduces significantly soluble adhesion molecules such as soluble intercellular adhesion molecules-1 (sICAM-1) and soluble E-cadherin (sE-cadherin) which play important role in tumor development, invasion and metastasis in HT-29 and Caco-2 transformed human epithelial colorectal cell line cultures (Parafiniewicz et al., 2012), thus it was of interest to validate any possible correlation between
EpCAM expression, and the tumor inhibiting significances of celecoxib at different stages of colon carcinogenesis in vivo. Because there were no studies to date, to the best of our knowledge, on the efficacy of celecoxib on colon CSCs during the promotion/progression stages of carcinogenesis, at which surrogate premalignant lesions are known to have developed, it was important to verify its action with colon CSCs at early stages in comparison to late stages of colon carcinoegnsesis, and whether celecoxib treatment can still be effective long after cancer initiation.

In biotechnology, flow cytometry is a laser-based, biophysical technology employed in cell counting, cell sorting, biomarker detection and protein engineering (Basiji et al., 2007). Flow cytometry is used to characterize CSCs using its specific biomarkers both quantitatively and qualitatively. It is also used to estimate the CSC characteristics that can be measured including cell size, cytoplasmic complexity, DNA or RNA content, cell cycle and a wide range of membrane-bound and intracellular proteins (Tagde et al., 2014).

Consequently, this study focuses on the role of the CSCs during the multi-step phases of initiation and progression of chemically induced colon carcinogenesis in experimental rats. This study also includes studying the effects of specific anti-COX-2 drug (celecoxib) on the CSCs' behavior during colon carcinogenesis in short and medium-term colon carcinogenesis bioassays in rats.

\section{Materials and Methods}

Healthy, 6 -week-old male Sprague-Dawley (S.D.) rats obtained from The Holding Company for Biological Products \& Vaccines (Vaccera), Helwan- Egypt, were allocated to plastic cages covered with metal grids with wood chips for bedding and allowed to acclimate for one week in the animal facility conditions at the Faculty of Science, Tanta University, before being divided into groups for experimentation. All experimental protocols were in accordance with the Guidelines for Ethical Care of Experimental Animals. The institutional animal care and use facility and the Zoology department's council of the Faculty of Science, Tanta University, Egypt approved the experimental design.. Target values for temperature and relative humidity were about $22 \pm 1^{\circ} \mathrm{C}$ and $55 \pm 5 \%$ respectively, and light-dark (day/night) cycle. The rats were given drinking tap water and balanced experimental pelleted animal food ad libitium. Animals were carefully observed every day and their body weights, food consumption and water intakes were measured precisely every week to evaluate any signs of toxicity or abnormality during the experiment.

\section{Initiation of rat multi-step colon carcinogenesis:}

1,2-Dimethylhydrazine dihydrochloried (DMH. 2HCl) was purchased from Sigma - Aldrich, St. Louis, MO, (USA). Animals were given subcutaneous (s.c.) injections of DMH dissolved in normal saline solution $(0.9 \%), 20$ $\mathrm{mg} / \mathrm{kg}$ body wt., once a week for 4 weeks for the short term experiment I ( 12 weeks), and $40 \mathrm{mg} / \mathrm{kg}$ body wt, once a week for 8 weeks for the long term experiment II 
(32 weeks).

Treatment with celecoxib as specific therapy during rat colon carcinogenesis

HPLC grade celecoxib (Sigma - Aldrich, St. Louis, MO, USA) dissolved in physiological $0.9 \%$ saline solution was given intraperitoneally (i.p.) to animals at a $50 \mathrm{mg} / \mathrm{kg}$ body wt. dose, day after day for either 4 weeks (for experiment I) or for 12 weeks (for experiment II) starting two days after the cessation of the carcinogen administration.

\section{Experimental protocols}

After chemical initiation of colon carcinogenesis, rats of each experiment were divided into four groups as follows: Group 1 (15 rats) were injected with DMH and served as positive control. Group 2 (15 rats) were injected with DMH then post treated with celecoxib $(50 \mathrm{mg} / \mathrm{kg}$ b.wt.). Group 3 (10 rats) were injected with celecoxib only in a post-initiation stage by the same protocol as mentioned in the previous step. Group 4 (10 rats) were non-treatment control injected with the vehicle $(0.09 \%$ saline).

\section{Termination, tumor evaluation and histopathology}

All rats in both experiments were sacrificed after either 12 or 32 weeks under excess of ethyl ether anesthesia. Gross examinations were performed macroscopically on all rats during sacrifice. Absolute and relative organ weights (organ wt/b.wt x 100) of all rats were taken for the kidneys and livers after organs being necropsied. Specimens from the liver, kidneys and colons were preserved in $10 \%$ phosphate-buffered formalin. Abnormal masses or lesions, were collected from the colons and kept in the same fixative until routinely prepared for histopathological examination. To evaluate tumor volumes (v), the long (L) and short (w) dimensions (mm) of each tumor mass (length and width) were measured with calipers and calculated according to the equation: $\mathrm{V}=$ (L X W2/2) (Shen et al., 2004). After embedding in paraffin wax, 4-5 $\mu \mathrm{m}$ sections of the collected tissues were stained with haematoxylin and eosin for a complete histopathological examination.

\section{Preparation of the colon and ACF counting}

At necropsy, the entire colon was removed, inflated with saline solution then opened longitudinally and rinsed in saline. For ACF assay, Cecum was excised and the remaining colon was divided into three segments representing three colonic regions, referred to as proximal colon (adjacent to the cecum), middle colon (mid colon) and distal colon (adjacent to the rectum). The length and width were determined in each segment. Each segment was fixed flat on filter paper in fresh $10 \%$ phosphate buffered formalin for at least $24 \mathrm{~h}$ at $4^{\circ} \mathrm{C}$ and then washed and stained with $0.1 \%$ methylene blue in water for $3 \mathrm{~min}$ for ACF counting. Specimens were carefully examined, mucosal side uppermost, by two pathologists at 200X and 400X magnifications under a compound light microscope. ACF that showed variations in its multiplicity, such as foci containing 1 crypt (1AC), foci with 2 or 3 crypts (2ACs and $3 \mathrm{ACs}$ ), or larger foci with- or more than 4 crypts ( $\geq 4 \mathrm{ACs}$ ), which are likely believed to progress into tumors (Corpet and Tache 2002), were counted and separated in categories. The number of ACF was determined, and their distribution patterns along the colon and crypt multiplicities were scored. After ACF counting, 2 pieces of each of the three colonic segments, proximal, mid and distal colons from each rat were embedded in paraffin, stained with $\mathrm{H} \& \mathrm{E}$ and examined for histopathological or immunohistochemical changes.

\section{Immunohistochemistry (IHC) for PCNA, EpCAM, CD133 and CD44}

The avidin-biotin complex method was used to demonstrate PCNA, EpCAM, CD133 and CD44 in $4 \mu \mathrm{m}$ sections of each part of colon tissues (Hsu, 1981). Sections were dewaxed with xylene and hydrated through a graded ethanol series, rinsed in sodium citrate buffer ( $\mathrm{pH}$ 6.0) and then were heated till boiling in an autoclave then cooled for antigen retrieval (repeated more than once). The sections were then treated with $0.3 \%$ hydrogen peroxide, normal horse serum, anti-PCNA rabbit polyclonal antibody (Product. No. SAB2108448, Sigma Aldrich) at 1:500 dilution, anti-EpCAM [E144] rabbit monoclonal antibody (Cat. No. ab32392; Abcam) at a dilution of 1:1000, antiCD133 (prominin-1) rabbit polyconal antibody (Cat. No. ab19898, Abcam) at 1:150 dilution or anti CD44 rabbit polyconal antibody (Cat. No. ab157107 Abcam) at 1:1000 dilution, for overnight at $4^{\circ} \mathrm{C}$. All sections were then washed with TBS-T and subjected to ABC-peroxidase procedures (ABC Kit; Vector Laboratories); the sections were sequentially treated with $0.3 \%$ hydrogen peroxide. As a negative control, normal serum was used instead of primary antibodies while Skim milk was used with the EpCAM antibody instead of the primary antibody. Immune complexes for all IHC reactions were visualized with 3,3'-diaminobenzidine tetrahydrochloride (DAB) as a chromogen. The sections were counterstained with Mayer's hematoxylin to facilitate examination under a light microscope.

IHC evaluation and generation of labeling indexes (LI)

To evaluate the labeling indexes for the dedicated antibodies (PCNA, CD133 and CD44), numbers of positively stained nuclei or cells in all apparently complete crypts found in every section were counted and divided by the total number of nuclei of each crypt X100 to generate LI (\%). As the EpCAM IHC staining expression was cytoplasmic or intracellular, a system for evaluation and grading IHC patterns was used by two investigators to determine quantitative estimation of IHC staining, with multiple values for extent and intensity for a score of 0 to 9 was performed as previously described (Malmstrom et al., 1988). The extent of staining was scored on a semiquantitative scale of 0 to 3 , using the following criteria: 0 , no detectable staining; $1,<10 \%$ scattered cells; $2,>$ $10 \%$ but $<50 \%$ stained cells; 3 , homogeneous staining in $>50 \%$ of cells. The intensity of staining was scored using the following criteria: 0 , no detectable staining; 1 , weakly stained cytoplasm and/or nuclei; 2, moderately stained cytoplasm and/or nuclei; 3, strongly stained 
cytoplasm and/or nuclei. Final scores were derived from multiplication of extent by intensity. Estimation of IHC was performed by two pathologists in a blind fashion without knowledge of the patient groups.

Determination of Aldehyde Dehydrogenase Concentration in colonic epithelium by ELISA

ELISA kit for Rat Aldehyde Dehydrogenase (ALDH1) with Catalog Number: MBS724302 (MyBiosource, San Diego, California, USA), was used for tissues samples. For this assay, colon mucosa homogenate samples obtained from different groups were rinsed in ice-cold PBS $(0.02 \mathrm{~mol} / \mathrm{L}, \mathrm{pH} 7.0-7.2)$ to remove excess blood thoroughly and weighed before homogenization. Minced the tissues to small pieces and homogenized them in a certain amount of PBS with a glass homogenizer on ice. The resulting suspension was subjected to ultrasonication to further break the cell membranes. After that, the homogenates were centrifuged for $15 \mathrm{~min}$ at $1500 \times \mathrm{g}$ (or $5000 \mathrm{rpm}$ ). The supernatant was removed and assayed immediately while remaining samples were stored at $-20^{\circ} \mathrm{C}$ or $-80^{\circ} \mathrm{C}$. The Optical Density (O.D.) was determined immediately at $450 \mathrm{~nm}$ using an ELISA microplate reader (iMark $^{\mathrm{TM}}$ Microplate Absorbance Reader, BIO-RAD, USA). A standard curve was plotted relating the intensity of the color (O.D.) to the concentration of standards. The $\mathrm{ADH}$ concentration in each sample was interpolated from its standard curve (Kuniyasu et al., 2003).

\section{Flow cytometry}

Aliquots of mucosal cells (about one gram in weight) were scrapped from the colon of rats from different groups by clean slide glasses, suspended in PBS, moved on ice freshly to the flow cytometer at Mansoura University Children's hospital, Genetics Department, Flow Cytometry unit (Flourescence activated cell sourcing (FACS) caliber flow cytometer, Becton Dickinson, Sunnyvale, CA, USA) equipped with a compact air cooked low power $15 \mathrm{mw}$ at argon ion laser beam (488nm). For this assay (Nautiyal et al., 2012), the average number of evaluated nuclei per specimen was 20,000 and the number of nuclei scanned was 120 per second. DNA histogram derived from flow cytometry was obtained with a computer program for Dean and Jett mathematical analysis (Dean and Jett, 1974).

Cell cycle analysis by flow cytometry using propidium iodide DNA staining:

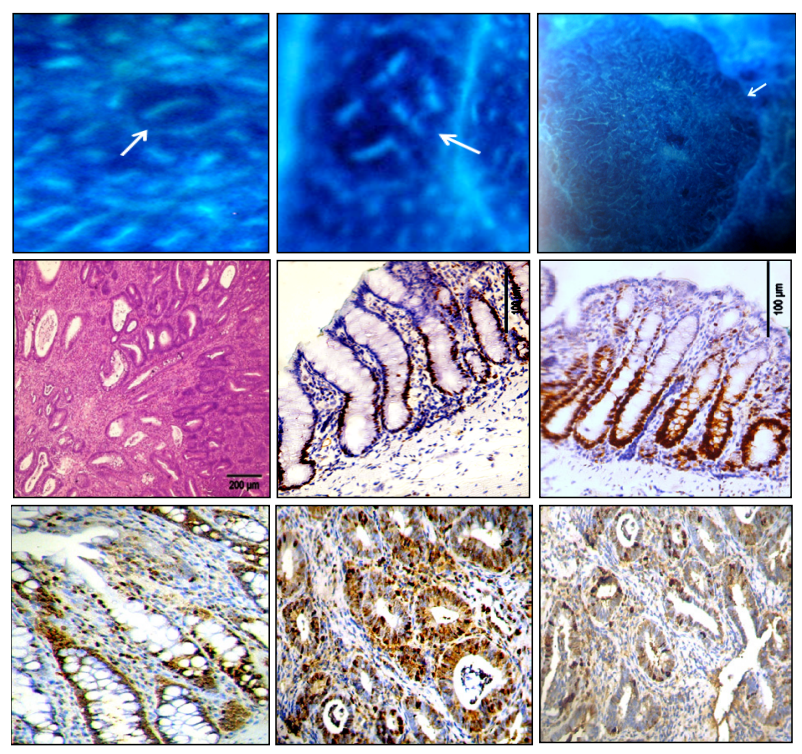

Figure 1. Photomicrographs showing: Methylene Blue Stained whole Mount of the Colon. X400 (A-C); A): Aberrant crypt focus with $1 \mathrm{AC}, \mathrm{B})$ : Large ACF, C): A colon tumor. X400; C): Colon adenocarcinoma after 32 weeks. HE, X200; (E-I): PCNA IHC, E): Normal colon (12 weeks). X200, F): DMH-initiated colonic crypts with increased proliferating zones. X200, G): Hyperplastic poly after 32 weeks showing increased PCNALI\%. X400, H): Adenocarcinoma from a DMHtreated rat showing high PCNA LI\%.X200, I): Adenocarcinoma from a rat treated with Celecoxib after DMH with lower PCNA affinity. X200

Table 1. Induction of ACF in the Colons of Rats Treated with DMH, and/or Celecoxib After 12 Weeks (Experiment I)

\begin{tabular}{|c|c|c|c|c|c|c|c|}
\hline \multirow[t]{2}{*}{ Group } & \multirow[t]{2}{*}{ Treatment } & \multirow{2}{*}{$\begin{array}{c}\text { No. of } \\
\text { Rats }\end{array}$} & \multirow[t]{2}{*}{ Total No. of ACF } & \multicolumn{4}{|c|}{ No. of Aberrant Crypts per Focus } \\
\hline & & & & $1 \mathrm{ACs}$ & $2 \mathrm{ACs}$ & $3 \mathrm{ACs}$ & $\geq 4$ ACs \\
\hline G1 & DMH & 15 & $192 \pm 51.5^{*}$ & $97 \pm 28.5$ & $51 \pm 12.8$ & $28.5 \pm 12$ & $15.5 \pm 10.7$ \\
\hline $\mathrm{G} 2$ & $\mathrm{DMH}+$ Celecoxib & 15 & $69 \pm 23.8^{*}$ & $37.6 \pm 14.8^{*}$ & $17.6 \pm 7 *$ & $8.4 \pm 6.6^{*}$ & $5.2 \pm 6.0^{*}$ \\
\hline G3 & Celecoxib & 10 & 0 & 0 & 0 & 0 & 0 \\
\hline G4 & 0.09\% Saline & 10 & 1 & 0 & 1 & 0 & 0 \\
\hline
\end{tabular}

a: Means \pm S.D.; *: Significant vs. G1 at P $\leq 0.05$; ACs: Aberrant crypts

Table 2. Induction of ACF in the Colons of Rats Treated or Not with DMH, and/or Celecoxib After 32 Weeks (Experiment II)

\begin{tabular}{llcccccc}
\hline Group & Treatment & No. of Rats & Total No. of ACF & \multicolumn{3}{c}{ No. of Aberrant Crypts per Focus } \\
\cline { 3 - 7 } & & & & 1AC & 2ACs & $3 \mathrm{ACs}$ \\
\hline G1 & DMH & 10 & $320.7 \pm 48.4 *$ & $152 \pm 28.6$ & $59.8 \pm 55.1$ & $48.7 \pm 51.2$ & $60.3 \pm 45.7$ \\
G2 & DMH + Celecoxib & 10 & $148.6 \pm 39.7 *$ & $64.6 \pm 15.8 *$ & $31.4 \pm 23.5 *$ & $27.4 \pm 22.2 *$ & $25.2 \pm 20.0 *$ \\
G3 & Celecoxib & 5 & $2.0 \pm 1.0$ & $2.0 \pm 1.0$ & 0 & 0 \\
G4 & 0.09\% Saline & 5 & 0 & 0 & 0 & 0 \\
\hline
\end{tabular}

a: Means \pm S.D.; *: Significant vs. G1 at P $\leq 0.05 ;$ AC: Aberrant crypt 
The staining of mammalian DNA for flow cytometry was performed according to (Traganos et al., 1977). The premise of these dyes is that they are stoichiometric, i.e. they bind in proportion to the amount of DNA present in the cell. In this way cells that are in $\mathrm{S}$ phase will have more DNA than cells in G1. They will take up proportionally more dye and will fluoresce more brightly until they have doubled their DNA content. The cells in G2 will be approximately twice as bright as cells in G1. Briefly, after at least 12 hour of fixation by $70 \%$ ethanol the samples were again centrifuged, excessive ethanol was removed by twice washing with PBS. $200 \mu 1$ of cell suspension in citrate buffer was placed in a $5 \mathrm{ml}$ tubes. The solution of propidium iodide $(0.05 \mu \mathrm{l} / \mathrm{ml})$ was protected against light with tinfoil during preparation, storage and the staining procedure. The solution was mixed and the sample was filtered $(12 \times 75 \mathrm{~mm}$, cat. no.2058, falcon comp). The samples were run in the flow cytometer within 1 hour after the addition of propidium iodide and the stained samples were stored overnight in room temperature to measure the sub G1 for apoptosis (\%) in the same tubes. The dot plot curves obtained were expressed as log ratios (X bar was expressed as FL2-H=CD133, and $\mathrm{Y}$ bar was expressed as

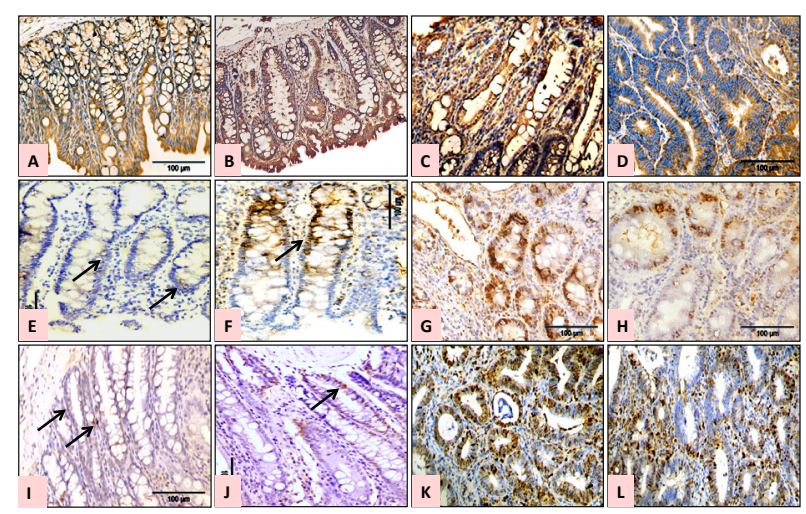

Figure 2. Photomicrographs Showing IHC Staining. (A-D): EpCAM IHC: A): Normal colonic epithelium. X200, B): DMH-induced colonic epithelium after 12 weeks. X200, C): Hyperplastic polyp. After 32 weeks. X200, D): Colon adenocarcinoma treated with celecoxib. X400; E-H): CD133 IHC: E): Normal colonic epithelium after 12 weeks. X200; F): DMH-treated colonic epithelium. X200, G): Adenocarcinoma after 32 weeks. X200, H): Adenocarcinoma treated with celecoxib showing less CD133 IHC affinity.X400; I-L): CD44 IHC: I): Normal colonic epithelium after 12 weeks showing less numbers of CD44-positive cells. X200, J): DMH-treated colonic epithelium after 32 weeks showing high numbers of CD44positive cells. X200, k): Adenocarcinoma from DMH-treated rat showing strong CD44 positivity. X200,L): Adenocarcinoma from a rat treated with celecoxib showing lower cd44 affinity. $\mathrm{X} 200$
FL1-H= CD44). Apoptosis log ratios were detected twice between the numbers of cell counts, once against the $\mathrm{Y}$ bar of FL1-H and once of FL2-H (Levi et al., 2004).

\section{Statistcal analyses}

Groups data expressed as means \pm S.D. were analyzed using the two-tailed t-test or ANOVA analyses. Data expressed as percentages were analyzed using the Chi squared $\left(X^{2}\right)$ analysis using the Statistical Package for Social Science (SPSS) version 16, USA.

\section{Results}

Average numbers of ACF after 12 and 32 weeks:

Tables $(1 \& 2)$ summarize the data of induction and development of ACF in all groups. All animals treated with DMH showed 100\% incidence of ACF in both experiments (Figure 1), in contrast to almost complete lack of such lesions in the control animals except one focus with 2 ACs were seen in the mucosa of Group (4) of experiment (I) and two with $1 \mathrm{AC}$ in Group (3) of experiment (II). In experiment (1), DMH induced 192.1 $\pm 51.1 \mathrm{ACF}$ per rat in Group (1) and 69.6 23.8 ACF per rat in group (2) after celecoxib treatment. celecoxib inhibited significantly the small ACF containing 1, 2 or 3 aberrant crypts (ACs) as well as large foci containing $\geq 4$ aberrant crypts ( $\geq 4$ ACs) (Table 1). In experiment (2), the total ACF numbers counted in the entire colons of the DMH-treated rats were markedly higher than those found in the short term experiment (I). The figures were $320.7 \pm 48.4$ in Group (1) and 148.6 \pm 39.7 in Group (2) treated with celecoxib. Again, the total numbers as well as the numbers of aberrant crypts containing $1,2,3$ and $\geq 4 \mathrm{ACs}$ were significantly reduced by celecoxib treatment as compared to the DMH

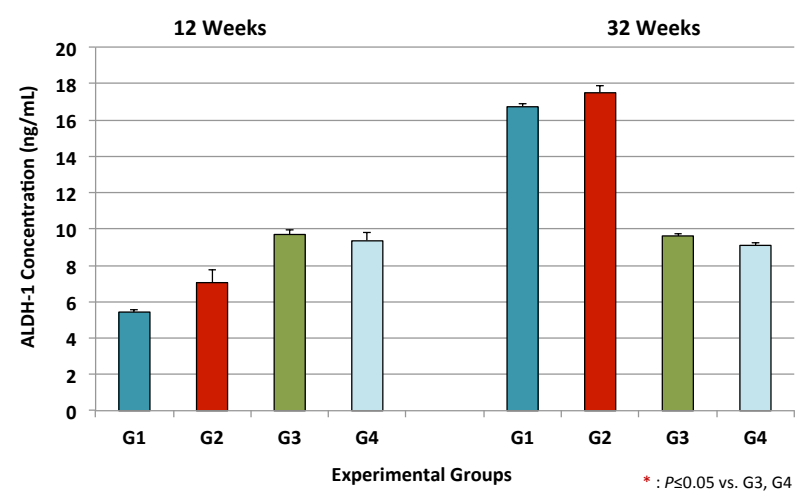

Figure 3. Concentration of ALDH-1 in the Colonic Epithelium of rats Treated or not with DMH and/or Celecoxib after 12 and 32 Weeks

Table 3. Tumor Incidences (\%), Multiplicities and Volumes (Experiment II)

\begin{tabular}{llcccc}
\hline Group & Treatment & No. of Rats & Tumor Incidence $(\%)^{\mathrm{a}}$ & Tumor Multiplicity & Tumor Volumes $\left(\mathrm{cm}^{3}\right)$ \\
\hline G1 & DMH & 15 & $8 / 15^{\mathrm{c}}(53.3 \%)^{\mathrm{d}}$ & $19 / 8(2.4 \pm 1.2)^{*}$ & $0.62 \pm 21.3^{*}$ \\
G2 & DMH + Celecoxib & 15 & $5 / 15(33.3 \%)$ & $6 / 5(1.2 \pm 1.0)$ & $0.33 \pm 11.2$ \\
G3 & Celecoxib & 10 & 0 & 0 & - \\
G4 & 0.09\% Saline & 10 & 0 & 0 & - \\
\hline
\end{tabular}

(a): Incidence: No. of tumor-bearing rats/ No. of rats per group (\%); (b): Multiplicity: Total No. of tumors /No. of tumor-bearing rats; (c): Gross tumor numbers regardless histology. (d): Percentage of rats bearing tumors in test group; *: Significant versus G2 at P $\leq 0.05$ 
only- treated Group (1) (Table 2).

Tumor incidences (\%), multiplicities and volumes (Experiment II)

No colon tumors were detected after the 12 weeks (short-term) assay of carcinogenesis (experiment I) except a very few hyperplastic polyps in different places, while various colon tumors were harvested after the medium-term 32 weeks assay (experiment II) (Figures 1-2). Histologically, the tumors found in all groups were adenomatous polyps, adenomas, dysplastic polyps, invasive adenocarcinomas and one mucinous carcinoma from Group (1). The tumor incidence was reduced from

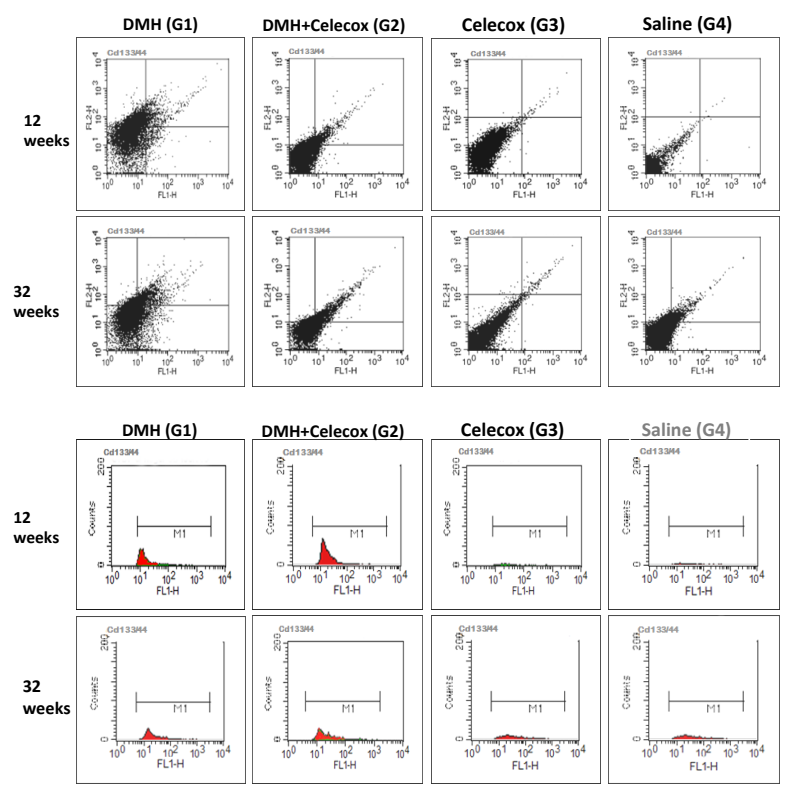

Figure 4. Upper 8 figures are representative flow cytometry dot plot figures for log data showing the percentages of CD133 and CD44 positive cells after 12 and 32 weeks. Lower 8 figures are representative flow cytometry plot figures for apoptotic cell numbers after 12 and 32 weeks. FL1-H: CD133; FL2-H: CD44; M1: apoptotic cells
$53.3 \%$ in Group (1) to $33.3 \%$ after celecoxib treatment in Group (2); The figures did not reach statistical significance while significant reduction in the tumor volumes and tumor multiplicities were evident in the tumor-bearing rats after celecoxib treatment as compared to Group (1) (Table 3).

IHC of cellular proliferation and cancer stem cell markers Proliferating cell nuclear antigen labeling indexes (PCNA-LI \%): The PCNA-positive nuclei were mainly restricted in the lower one third of the colonic crypts of non-treated animals (Figure 1, E-I). DMH treatment generally increased the length of the proliferating zone in the colonic crypts to the middle and the upper thirds. Generally, the LI were significantly higher in all DMHtreated colons over the corresponding non-treated controls $(\mathrm{P} \leq 0.05)$. In most DMH-treated rats, PCNA-LI were significantly less in the areas of the proximal colons when compared with the areas of the mid and distal colons $(\mathrm{P} \leq 0.05)$. In general, celecoxib treatment inhibited the PCNA LI (\%) in the colonic epithelium after DMH treatment in both experiments (I and II) (Tables $4 \& 5$ ). In tumors, PCNA-LI were significantly inhibited in tumors treated with celecoxib as compared to the tumors from Group (1) (Table 5).

\section{EpCAM IHC scores}

Tables ( 4 \& 5) show IHC scores of EpCAM in the colonic epithelia and tumors of both Experiments (I \&II). EpCAM IHC staining showed a dispersed pattern across the cell membranes, while sometimes was also confined to the intercellular spaces between cells of the colonic epithelium (Figure 2,A-D). Some cytoplasmic and scantly nuclear IHC reaction was detected in DMH-treated colonic epithelia and in tumors but not in the non-carcinogen treated controls. Tumors showed heterogeneous expression; some cells had higher EpCAM expression than other cells in the same tumor. In both experiments, in general, the expression pattern of EpCAM was significantly higher

Table 4. Immunohistochemical Data of the Colonic Epithelia Treated or Not with DMH, and/or Celecoxib After 12 Weeks (Experiment I).

\begin{tabular}{|c|c|c|c|c|c|}
\hline Groups & Treatment & PCNA LI (\%) & EpCAM (Scores) & CD44 LI & CD133 LI \\
\hline & & & & $(\%)$ & $(\%)$ \\
\hline G1 & DMH & $54.3 \pm 0.3 *$ & $6.0 \pm 1.01^{\mathrm{a}, *}$ & $7.53 \pm 1.7 *$ & $12.07 \pm 2.7 *$ \\
\hline $\mathrm{G} 2$ & $\mathrm{DMH}+$ Celecoxib & $41.3 \pm 6.5$ & $4.5 \pm 1.73$ & $4.9 \pm 0.4$ & $6.57 \pm 3.5$ \\
\hline G3 & Celecoxib & $36.3 \pm 6.1$ & $1.6 \pm 0.26$ & $2.4 \pm 0.8$ & $1.0 \pm 0.87 * *$ \\
\hline G4 & Saline & $30.3 \pm 0.2$ & $2.0 \pm 1.0$ & $1.5 \pm 0.50$ & $2.9 \pm 1.1$ \\
\hline
\end{tabular}

Total No. of Cells measured $\geq 1000$ cell per slide; a: values are means \pm S.D. *: Significant vs. G2 at P<0.05; **: Significant vs. G4 at P $\leq 0.05$.

Table 5. Immunohistochemical data in the Colons and Tumors of Rats Treated or Not with DMH, and/or Celecoxib After 32 weeks (Experiment II)

\begin{tabular}{|c|c|c|c|c|c|}
\hline Groups & Treatment & $\%$ PCNA & EpCAM Scores & $\%$ CD44 & $\%$ CD 133 \\
\hline G1 & DMH & $55.5 \pm 2.6^{*}$ & $5.1 \pm 1.8 \mathrm{a}$ & $7.3 \pm 0.9 *$ & $14.9 \pm 5.1 *$ \\
\hline G2 & DMH + Celecoxib & $44.1 \pm 6.0$ & $6.1 \pm 0.3$ & $5.5 \pm 1.1$ & $8.2 \pm 5.1$ \\
\hline G3 & Celecoxib & $30.4 \pm 5.1$ & $3.5 \pm 0.7$ & $5.1 \pm 0.8$ & $5.5 \pm 1.1$ \\
\hline G4 & Saline & $21.5 \pm 1.3$ & $2.8 \pm 1.1$ & $4.7 \pm 0.6$ & $4.9 \pm 1.0$ \\
\hline Tumors & G1 (DMH) & $57.4 \pm 14.3 * *$ & $7.2 \pm 1.3 * *$ & $6.9 \pm 1.0 * *$ & $18.3 \pm 3.2 * *$ \\
\hline Tumors & G2 (DMH+Celecoxib) & $41.7 \pm 20.7$ & $4.0 \pm 2.1$ & $5.8 \pm 1.4$ & $10.2 \pm 2.1$ \\
\hline
\end{tabular}

Total No. of Cells measured $\geq 1000$ cell per rat; a: values are means \pm S.D. *: Significant vs. G2 at P $\leq 0.05$; **: Significant vs. G2 tumors at P $\leq 0.05$ 
in the DMH-treated groups as compared with the noncarcinogen treated control groups. In experiment (I), IHC expression of EpCAM was significantly higher in Group (1) treated with DMH as compared to the celecoxibtreated group (2). In contrast, in experiment (II), after 32 weeks, the IHC expression of EpCAM was slightly higher in the mucosal epithelium of Group (2) treated with celecoxib+DMH than in Group (1) treated with DMH only but without any statistical difference. Further, the expression of EpCAM was significantly lower in tumors of Group (2) treated with celecoxib as compared with the tumors from Group (1) (Figure 2, A-D). Generally, it was observed that the IHC expression was stronger in the hyperplastic, dysplastic polyps and adenomas than in the few numbers of adenocarcinomas found (Figure 2, C,D). Some colonic adenocarcinomas showed slightly week EpCAM IHC expression.

\section{CD133 (Prominin-1) labeling indexes (LI \%)}

IHC expression of CD133 was mostly membranous, however it sometimes showed a light cytoplasmic staining

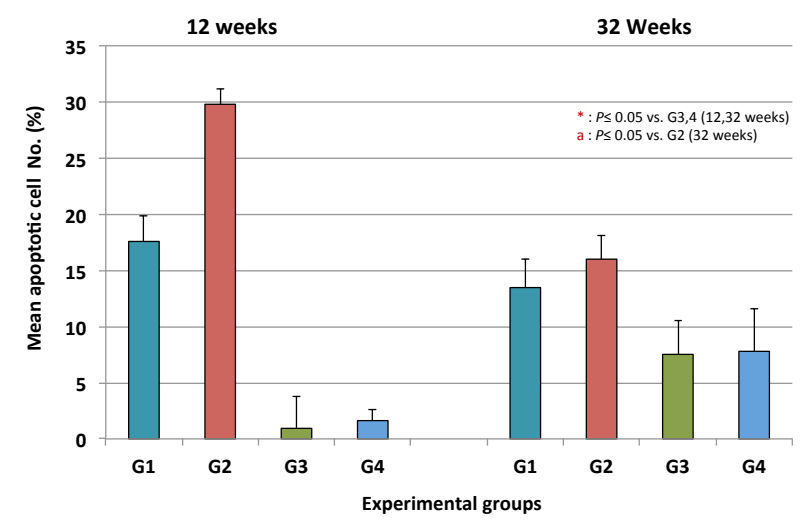

Figure 5. Flow Cytometry data for Mean Percentages of Apoptotic Cell Numbers $(\%)$ in the Colonic Epithelium of rats treated or not with DMH and/or Celecoxib after 12 and 32 "'eeks pattern in some cells (Figure 2 E-H). Staining was mostly evident in the basal parts of the colonic crypts in either the control, DMH-treated normally-appearing epithelium or in the hyperplastic and dysplastic polyps. In tumors such as adenocarcinomas, mucinous adenocarcinoma or carcinoma in situ (CIS), however, the staining pattern of CD133 was also membranous, slightly cytoplasmic and heterogeneously distributed within the different parts of the tumors. At the short term experiment (I), the CD133 labeling indexes (\%) (Table 4), were significantly higher in the DMH-treated epithelium of Group (1), however, treatment with celecoxib significantly reduced the LI\% in Group (2). The LI\% of Group (3) treated with celecoxib alone was almost similar to that of the control Group (4). Moreover, after 32 weeks (Table 5), the CD133 LI (\%) were significantly higher in the DMH-treated epithelium and in tumors than those treated with celecoxib alone or after DMH administration (Figure 2-b).

CD44 labeling indexes (LI \%) in the colonic epithelium

CD44 IHC staining pattern of CSCs was mostly nuclear, however it sometimes it showed a slight cytoplasmic staining pattern beside the nuclear staining (Figure 2 I-L). Staining was mostly evident in the lower two thirds of the colonic crypts either in the control, $\mathrm{DMH}$-treated normally-appearing epithelium or in the hyperplastic and dysplastic polyps. In tumors, the staining pattern of CD44 was also nuclear, slightly cytoplasmic and homogenously distributed within the different parts of the tumors. CD44 labeling indices (\%) in experiment (I) were slightly higher in the DMH- treated colonic epithelia, albeit without statistical significance when compared with the other groups (Table 4). In experiment (II), however, the CD44 LI\% were significantly higher in the DMH-treated epithelia and in tumors as compared with the other groups. Nevertheless, treatment with celecoxib after DMH rendered the CD44 LI\% to be significantly reduced in both normally appearing DMH-treated epithelia and tumors (Table 5).

Table 6. Percentage of Cells Positive for CD44 and CD133 by Flow Cytometry After 12 Weeks (Experiment I )

\begin{tabular}{lllcccc}
\hline Group & Treatment & $\mathrm{n}$ & $\begin{array}{c}\text { \% Cells Positive for } \\
\text { CD44 (UL) }\end{array}$ & $\begin{array}{c}\text { \% Cells Positive for } \\
\text { CD133 (LR) }\end{array}$ & $\begin{array}{c}\text { \% Cells Positive for } \\
\text { Both (UR) }\end{array}$ & $\begin{array}{c}\text { \% Cells Negative for } \\
\text { Both (LL) }\end{array}$ \\
\hline G1 & DMH & 5 & $7.68 \pm 1.99 \mathrm{a}$ & $17.81 \pm 2.17 \mathrm{a}, *$ & $18.57 \pm 1.72 *$ & $55-81 \pm 2.94$ \\
G2 & DMH + Celecoxib & 5 & $6.89 \pm 1.04$ & $5.62 \pm 0.98$ & $11.11 \pm 0.90$ & $76.38 \pm 1.5$ \\
G3 & Celecoxib & 3 & $0.09 \pm 1.05 * *$ & $0.53 \pm 1.2 * *$ & $1.04 \pm 0.70^{* *}$ & $98.34 \pm 2.01$ \\
G4 & 0.09\% Saline & 3 & $0.01 \pm 0.30$ & $0.05 \pm 0.60$ & $0.08 \pm 0.20$ & $99.86 \pm 0.19$ \\
\hline
\end{tabular}

Total No. of Cells measured $=10000$ cell per test; $n=$ No. of samples tested in each group.; a: values are percentage means \pm S.D. *: Significant vs. $\mathrm{G} 2$ at $\mathrm{P}<0.05 ; * *$ : Significant vs. $\mathrm{G} 4$ at $\mathrm{P} \leq 0.05$

Table 7. Percentage of Cells Positive for CD44 and CD133 by Flow Cytometry (Experiment II)

\begin{tabular}{|c|c|c|c|c|c|c|}
\hline Group & Treatment & $\mathrm{n}$ & $\begin{array}{l}\text { \% Cells Positive for } \\
\text { CD44 (UL) }\end{array}$ & $\begin{array}{l}\text { \% Cells Positive for } \\
\text { CD133 (LR) }\end{array}$ & $\begin{array}{c}\% \text { Cells Positive for } \\
\text { Both (UR) }\end{array}$ & $\begin{array}{c}\% \text { Cells Negative for } \\
\text { Both (LL) }\end{array}$ \\
\hline G1 & DMH & 5 & $32.45 \pm 3.9 \mathrm{a}, *$ & $4.07 \pm 1.58 \mathrm{a}, *$ & $7.09 \pm 2.12$ & $56.39 \pm 2.34$ \\
\hline G2 & DMH + Celecoxib & 5 & $5.75 \pm 0.94$ & $13.44 \pm 1.96$ & $17.32 \pm 2.9^{*}$ & $63.49 \pm 1.1$ \\
\hline G3 & Celecoxib & 3 & $1.8 \pm 0.69 * *$ & $0.74 \pm 1.64 * *$ & $2.23 \pm 1.66^{* *}$ & $95.23 \pm 1.61$ \\
\hline G4 & $0.09 \%$ Saline & 3 & $0.04 \pm 3.10 *$ & $0.24 \pm 1.80$ & $0.39 \pm 2.30$ & $99.33 \pm 2.20$ \\
\hline
\end{tabular}

Total No. of Cells measured $=10000$ cell per test; $n=$ No. of samples tested in each group.; a: values are percentage means \pm S.D. ${ }^{*}:$ Significant vs. $\mathrm{G} 2$ at $\mathrm{P}<0.05 ; * *$ : Significant vs. $\mathrm{G} 4$ at $\mathrm{P} \leq 0.05$ 
Aldehyde Dehydrogenase (ALDH-1) Concentration levels in the colonic epithelium

The mean data relating the intensity of the color (O.D.) to the concentration of standards resulting in the ALDH-1 concentration in each sample are shown in Figure (3). In experiment (I), the DMH- treatment in general have decreased the ALDH-1 concentration levels in the colonic epithelia of both Groups (1) and (2) as compared with their corresponding control groups respectively, with no intergroup differences between Groups (1) and (2). Moreover, the ALDH-1 concentration levels did not differ by celecoxib treatment after DMH in Group (2) as compared with Group (1) treated with DMH only. In experiment (II), in contrast, the ALDH-1 concentration levels were significantly increased in the DMH- treated groups as compared with the control groups with no differences between the data of Groups (1) and (2). In general, ALDH-1 concentration did not differ between $\mathrm{DMH}$ and DMH + celecoxib treated groups in both experiments.

Flow cytometry analysis data for CD44 and CD133 cell counts

The dot plots of log data obtained from the flow cytometry analysis (Figure 4) revealed that the percentages of CD44 and CD133 positive cells were significantly higher in the DMH-treated as compared with the noncarcinogen treated groups after 12 and 32 weeks (Tables 6 \& 7). The percentages of CD44-positive cells in Group (1) treated with DMH only were markedly higher $(32.45 \%)$ after 32 weeks (Table 7) as compared with that of the 12 weeks $(7.68 \%$ ) (Table 6), with the normal control levels were $0.04 \%$ and $0.01 \%$ respectively. In contrast, the percentages of CD133-positive cells were higher in Group (1) after 12 weeks $(17.81 \%)$, and then it was reduced in Group (1) after 32weeks $(4.07 \%)$. celecoxib treatment after DMH did not affect the percentages of CD44-positive cells after 12 weeks however it has obviously reduced the numbers of CD44 positive cells after 32 weeks to $5.75 \%$ which were still significantly higher than the normal control levels $(0.04 \%)$. In contrast, the numbers of CD133 positive cells were reduced by celecoxib treatment after 12 weeks $(5.62 \%)$ while it was increased after 32 weeks $(13.44 \%)$. In Groups (3 and 4) which were not treated with $\mathrm{DMH}$, the celecoxib treatment have increased the percentages of both CD44 or CD133 cells after 12 and 32 weeks as compared with the normal control of Group (4) (Tables 6 and 7).

Cell cycle analysis data for apoptosis by flow cytometry

The mean numbers of apoptotic cells detected by flow cytometry were generally higher in the DMH-treated groups as compared with the non-carcinogen treated groups after 12 or 32 weeks. The numbers of apoptotic cells were significantly higher after 12 weeks than 32 weeks (Figures 4,5). Treatment with celecoxib after DMH has induced apoptosis significantly by $47.4 \%$ after 12 weeks, and by $8.4 \%$ after 32 weeks as compared with the DMH-only treated corresponding groups. The induction of apoptosis by celecoxib was higher after 12 weeks than 32 weeks by about $48 \%$.

\section{Discussion}

Understanding the characteristics of CSCs and the mechanisms that underlie the self-renewal behavior of CSCs is of greatest importance for discovery and development of anticancer drugs targeting CSCs. CSCs are broadly believed to ascend from the normal stem cells or progenitor cells during mutation(s). During development, certain molecular signaling pathways such as Wnt, Notch and Hedgehog were proposed to play an important part in the recurrence and maintenance of CSC (Yapeng and Liwu, 2012). CSCs possess not only the capacity to self-renew but also differentiate and can upsurge to heterogeneous tumors. Two recent transgenic animal studies have shown that colon crypt stem cells are the cell of origin of epithelial intestinal cancers (Barker et al., 2009; Zhu et al., 2009). Eradicating cancer stem cells, the core of cancer origin and recurrence, has been supposed as auspicious approach to advance cancer survival or even to cure cancer patients.

The present study is an attempt to track the role of certain CSC biomarkers during the initiation and progression processes of colon carcinogenesis in experimental animals. The study also included learning the role of specific anti-COX-2 drug (celecoxib) on the CSCs' behavior during the multistep colon carcinogenesis stages. Two experiments were performed, the first, a short term12 week study which represented the initiation process of colon carcinogenesis in which only the preneoplastic lesions; aberrant crypt foci (ACF) should be formed. ACF are end point biomarkers for colon carcinogenesis (Patlolla et al., 2012). The other experiment was a medium term colon cancer bioassay in which the tumors were formed after 32 weeks, mostly adenocarcinomas. The expression patterns of different biomarkers believed to correlate with CSCs were investigated during the two stages of carcinogenesis and compared in relation to the effect of the COX-2 inhibitor celecoxib .

Colon carcinogenesis is a multistep process caused by a sequence of genetic or subsequent epigenetic alterations that are vital to dissimilar stages from initiation to promotion and progression of cancer development (Fearon and Vogelstein, 1990). ACF are recently used as effective surrogate biomarkers for experimentally detection of cancer promoters or chemopreventive agents against colorectal cancers (Fernandes et al., 2011; Al-Henhena et al., 2015). Recently, evidence has also shown that ACF can be effectively employed in chemopreventive studies in humans (Patlolla et al., 2012). ACF appear at an early period of colorectal carcinogenesis and in the tumor- bearing rodents after treatment with chemical carcinogens and in patients with familial adenomatous polyposis (FAP) and other bowel tumors (Roncucci, et al., 1991). Increased ACF size and frequency is closely related to tumor promotion (Tang, et al., 1996). Their dysplastic appearance, increased cell proliferation and high frequency of K-ras and p53 mutation (Losi, et al., 1996) point to a preneoplastic role of ACF during colorectal carcinogenesis in human and in rodents (O'Leary et al., 2011).

In the present study, ACF was successfully induced and 
measured in both experiments with expectedly significant higher numbers after 32 weeks. In both experiments, ACF numbers of large and small foci were markedly reduced after treatment with celecoxib, this is in line with previous results of Rao et al., (2009) who postulated that celecoxib alone or in combination in low-dose with other chemotherapeutic drugs significantly caused or enhanced colon cancer chemopreventive efficacy. In correlation, cellular proliferation was enhanced by DMH treatment and then it was reduced after celecoxib treatment as indicated by significant inhibition of the PCNALI (\%) in both experiments. Colon tumors, mostly diagnosed here as adenocarcinomas, were formed after 32 weeks in the DMH-treated groups, while the numbers and volumes of tumors were reduced significantly by celecoxib treatment along with a significant inhibition of cellular proliferation (PCNA LI \%) in the colonic epithelia and tumors. Recently, celecoxib was found to reduce colon cancer in Apc-mutant rats with a colitis-associated colon carcinogenesis (Kochi et al., 2015). The present study indicated that the inhibitory effects of the anti-COX-2 drug, celecoxib on colon carcinogenesis is correlated with subsequent down regulation of the cellular proliferation in the colonic epithelium which might have played a significant role in the inhibition of total numbers of ACF and subsequently on the incidences and volumes of the colonic tumors. This inhibition of ACF and the reduction of the tumor volumes respectively indicate that celecoxib in the present study affected not only the initiation but also the progression of colon tumors.

To understand whether the profound inhibitory effects of celecoxib for ACF and colon tumors are linked to the CSC populations in the colonic mucosa, several attempts were measured in the present study. ALDH-1 enzyme activity levels detected by ELISA here were almost similar in the colonic epithelia of rats treated with DMH and in normal controls after 12 weeks. In contrast, the ALDH-1 activity levels were significantly and sharply increased after 32 weeks as compared with the normal control levels, and as compared with the levels after 12 weeks. Also, the data showed that celecoxib did not affect the DMH-increased levels of ALDH-1 after 12 or 32 weeks. Huang et al., (2009), indicated that the rat's colon CSCs could be isolated on the basis of the expression of the ALDH-1 enzymatic activity. ALDH-1 is known as a detoxifying enzyme which has been recognized as a specific marker for normal and malignant human colonic stem cells. ALDH oxidizes intracellular aldehydes and thus confers resistance to alkylating agents (Dylla et al., 2008). Actually, the detoxification capacity of ALDH, by protecting $\mathrm{SC}$ against oxidative insult, might underlie the well-recognized longevity of SC. ALDH also converts retinol to retinoic acid, a modulator of cell proliferation, which may also modulate SC proliferation (Dylla et al., 2008).

ALDH-1-positive cells, which are scant and limited to the crypt bottom where stem cells reside, increase during transition of normal epithelium to adenoma or progression to carcinoma (Huang et al., 2009). This is in line with the present results of ALDH-1 increased activity in the colonic epithelium. However, it is clear that the inhibitory effect of celecoxib found here through COX-2 inhibition does not correlate with the detoxifying activity or the other mechanisms of ALDH-1 in the colonic epithelium. It is known that the mechanisms that control the growth and progression of CSCs and their stemness are controversial (Nautiyal et al., 2012). ALDH was investigated as a specific marker for identifying and isolating normal and malignant human colonic SC and as a way to quantify the number of SC cells over the course of colon cancer development (Boman et al., 2008a,b). Earlier report (Boman et al., 2004) using markers for crypt base cells (a SC-enriched subpopulation) provided biological evidence in support of ALDH-1 role as CSC marker.

Various studies have demonstrated that nonsteroidal anti-inflammatory drugs (NSAIDs) prevent colon cancer formation. Epidemiological cancer prevention studies suggest that there may be a decrease in mortality from colorectal cancer in regular users of NSAIDs. NSAIDs have also been shown to reduce the number and size of sporadic colon adenomas, which are the precursor lesions of colon cancer. Some NSAIDs have also been found to induce regression of adenomatous polyps in patients with FAP. However, there is no evidence showing that NSAIDs regress or cure colon cancer. These findings in human studies suggest that NSAIDs suppress colon carcinogenesis mainly at the adenoma stage (Pommergaard et al., 2015).

On the other hand, the present data revealed that the IHC expression pattern of EpCAM was many fold higher and significantly increased in the DMH-treated groups as compared to the non-carcinogen treated control groups in both experiments ( 1 and 2 ). The staining pattern in the carcinogen-treated tissues was membranous, cytoplasmic and sometimes nuclear. celecoxib treatment has significantly decreased the EpCAM expression in the colonic epithelium in experiment (1) after 12 weeks, but not to the control levels. In contrast, there were no inhibitory effects of celecoxib on EpCAM expression after 32 weeks. The expression pattern of EpCAM was stronger in the hyperplastic and dysplastic polyps than that of the studied adenocarcinomas. Here, the IHC scores summarized for all types of tumors together (polyps, adenomas and adenocarcinomas) showed that EpCAM scores were significantly reduced by celecoxib treatment. However, between adenocarcinomas, the difference between DMH-initiated tumors and celecoxib-treated tumors was statistically insignificant. Costabile et al., (2015) observed that primary colorectal cancer (CRC) cells lose expression of the E cadherin epithelial marker, which was instead expressed in cancer and normal colon mucosa of the same patient. The numbers of adenocarcinomas obtained after 32 weeks here were few to reach a final conclusion. EpCAM, the epithelial cell adhesion molecule was firstly discovered as a dominant antigen on colon carcinomas and was well-thought-out as a simple cell adhesion molecule and reliable surface-binding site for therapeutic antibodies. New findings can better elucidate the significance of EpCAM's high-level expression on human cancers and cancer propagating cells and their negative prognostic potential for survival of patients with definite cancers. EpCAM has oncogenic prospective and 
is activated by discharge of its intracellular domain, which is able to signal into the cell nucleus by assignation of elements of the wnt pathway (Munz et al., 2009).

Soluble adhesion molecules such as soluble intercellular adhesion molecules-1 (sICAM-1) and soluble E-cadherin (sE-cadherin) play important role in tumor progression, invasion and the development of metastasis (Parafiniewicz et al., 2012). It was observed that their concentrations in body fluids of patients with colon cancer were elevated. celecoxib was found to significantly reduce the soluble intercellular adhesion molecules; sICAM-1 and sEcadherin concentrations in HT-29 and Caco- 2 transformed human epithelial colorectal cell line cultures co-treated with phytic acid and TNF- $\alpha$. A decrease of cells adhesion property to collagen I was observed under the influence of celecoxib on cell cultures exposed to phytic acid or phytic acid plus TNF- $\alpha$ (Parafiniewicz et al., 2012). The relationship between celecoxib, cell adhesion properties and EpCAM could presumably explain the inhibitory effects of celecoxib on the tumor initiation and progression in the present experiment.

In a recent study, patients with gastric cancer demonstrated increased levels of sE-cadherin when compared with normal control subjects, and treatment of patients with resectable gastric carcinoma with celecoxib resulted in decreased levels of sEcadherin (Elzagheid et al., 2006). celecoxib intervention was associated with increased apoptosis and inhibition of angiogenesis (Parafiniewicz et al., 2012). It is known that expression of E-cadherin in the process of invasion and metastasis of gastrointestinal carcinomas is regulated by the COX-2 (Elzagheid et al., 2006). To the best of our knowledge, this is the first attempt to link EpCAM with anti-COX-2 inhibitors regarding effect on cell adhesion properties.

Another possible explanation of the role of EpCAM in colon carcinogenesis occurred in the present study is through the epithelial mesenchymal transition (EMT) pathway. EpCAM is known to demonstrate a part in the epithelial mesenchymal transition (EMT) in tumors, although its precise effects are still unwell understood. Its aptitude to overwhelm E-cadherin suggests that EpCAM would stimulate EMT and tumor metastasis, but its homotypic cell adhesion properties can thwart its ability to suppress E-cadherin (Patriarca et al., 2012). Results from diverse studies are regularly conflicting. In one study, for instance, silencing of EpCAM with short interfering RNA (siRNA) directed to a decrease of proliferation, migration, and invasion of mammary cancer cells in vitro (Osta et al., 2004), giving indication for the function of EpCAM in promoting EMT. In a different study, cells undergoing EMT were shown to downregulate EpCAM (Santisteban et al., 2009). This could clarify the down regulation of EpCAM expression in some tumors or dysplastic mucosal areas of the rat colon in the present study. In one previous study, epithelial tumors were regularly intensely positive for EpCAM, but mesenchymal tumors had only rare and weak positivity (Went et al., 2004). It has been suggested that EpCAM expression is downregulated during EMT but then upregulated once the metastasis reaches its future tumor site (van der Gun et al., 2010). In the present study,
EpCAM expression in Group (1) treated with DMH after 32 weeks was significantly $(\mathrm{P}<0.05)$ lower than that of Group (1) after 12 weeks. This could be explained by the EMT transition of some epithelial dysplastic areas turning into tumors thus causing a down regulation of EpCAM rendering lower expression. This may need further confirmation.

CD44 and CD133 CSC markers were evaluated here by IHC and by flow cytometry. Both CD44 and CD133 were reported as putative markers for isolating colorectal CSCs and of functional importance for colorectal CSCs (Lei Du, 2008). These cells were shown to have a greater ability to form clones in vitro and to initiate xenograft tumors in severe combined immunodeficient (SCID) mice (Bonnet, 2005). Many markers comprised CD44, CD133, CD24, and CD166 are expressed in other categories of normal cells. Between these markers, both CD44 and CD133 were broadly used for segregating CSCs from solid tumors. CD44 is a transmembrane glycoprotein which contributes to several cellular functions, such as growth, survival, differentiation, and motility (Cheng and Sharp, 2006). It is a distinct adhesion molecule and has a role in cancer cell migration and matrix adhesion in reaction to a cellular microenvironment, hence enhancing cellular aggregation and tumor cell growth (Aruffo et al., 1990).

Here, the numbers of CD44 and CD133 cells were isolated by flow cytometry (total no. of measured cells were 10000 cells for each marker). In the short term experimement (1) after 12 weeks and in the medium- term experimement (2) after 32 weeks, the percentages of CD44 positive cells in normal controls were as few as $0.01 \%$ and $0.04 \%$ respectively while that of the CD133 were $0.05 \%$ and $0.24 \%$ respectively. In the DMH-treated rats, the percentages of CD44 cells were increased sharply in the colonic epithelium to $7.68 \%$ and $32.45 \%$ respectively, while that of CD133 positive cells were also significantly increased to 17.81 and $4.07 \%$ respectively as compared with the control values. Interestingly, the treatment with celecoxib after DMH here has shown differential effects on both markers depending on the carcinogenesis stage. After 12 weeks, it did not affect the numbers of CD44 positive cells as compared with Group (1), however, after 32 weeks it significantly reduced the percentages of CD44 positive cells to $5.75 \%$. The percentage of CD133 positive cells was significantly reduced in Group (1) to $5.62 \%$ after 32 weeks. In contrast, the mean percentage of CD133 positive cells after treatment with celecoxib in Group (2) was increased from $4.07 \%$ in Group (1) to $13.44 \%$ in Group (2). In the normal epithelium without DMH treatment, a slight but statistically significant elevation in the percentages of CD44 and CD133 was noticed after treatment with elcecoxib in both experiments.

The flow cytometric analysis here has also shown interesting results for apoptotic cell numbers in both experiments after 12 or 32 weeks. In the DMH-treated groups, the numbers of apoptotic cells were significantly higher after 12 weeks than after 32 weeks. Treatment with celecoxib after DMH has induced apoptosis significantly by $47.4 \%$ after 12 weeks, and then was reduced to $8.4 \%$ after 32 weeks as compared with the DMH-only treated corresponding groups. The induction of apoptosis by 
celecoxib was higher after 12 weeks than 32 weeks by about $48 \%$. This data is in line with the results of Saini and Sanyal (2012), who showed that piroxicam, a traditional NSAID and c-phycocyanin, a newly discovered COX-2 selective inhibitor, constitute remarkable chemopreventive targets in mediating apoptosis in the DMH induced early rat colon carcinogenesis via regulating PI3-K/Akt/GSK$3 \beta /$ PTEN signaling pathways. A further correlation here should be clarified for the detection of the relationship between the effect of celecoxib on the oxidative stress markers and cellular turnover during DMH-induced colon carcinogenesis and its relationship with induction of apoptosis.

The IHC data for CD44 and CD133 in the present study was almost similar to that of the flow cytometry. The CD44 and CD133 LI (\%) in normal controls of experiment (I) after 12 weeks were significantly lower than those in the DMH-treated groups. Only, the treatment with celecoxib after DMH have decreased the $\operatorname{LI}(\%)$ of CD133, in contrast to increasing it in the flow cytometry data. After 32 weeks the trend of the data of flow cytometry and that of the IHC was almost similar. In many different reports, both CD44 and CD133 were used as markers for isolating colorectal CSCs. This incites the problem of whether the two markers are valid for colorectal CSCs. It is also questioned if these markers are of functional importance for colorectal CSCs. Clarification of this question and a well understanding of the properties of CSCs could be useful to improve enhanced therapeutic approaches against cancer. The slight recruitment of CD44 and CD133 cells after celecoxib treatment in control non-carcinogenic colon epithelium here could be explained in part by the work of Fhu et al., (2014) who reported that the neoplastic Hodgkin and Reed-Sternberg (HRS) cells in vitro secrete lymphotoxin- $\alpha(\mathrm{LT} \alpha)$ which acts on endothelial cells to upregulate the expression of adhesion molecules that are important for immune cell ( $\mathrm{T}$ cell) recruitment into lesional lymph nodes. LT $\alpha$ also enhances the expression of hyaluronan which preferentially contributes to the recruitment of CD4(+) CD45RA(+) naïve T cells under in vitro defined flow conditions. They postulated that this process is regulated by cyclooxygenase/nuclear factor- $x \mathrm{~B} /$ activator protein 1 signaling while the cyclooxygenase (COX) pathway is the dominant regulator of LTa production in HRS cells. Thus COX-2 inhibition in the present experiment could possibly increase the recruitment of some CD44 and CD133 cells in celecoxib-treated colons as compared with the normal control.

In conclusion, we considered the expression pattern of four putative markers of stem cells in two early stages of DMH-induced colon carcinogenesis in rats. Our results show that ALDH-1, EpCAM, CD44 and CD133 are differentially expressed or up-regulated from the very early phases of colon carcinogenesis i.e. during formation of the precancerous lesions, ACF and in colon tumors. We identified that the ALDH-1 activity was down-regulated at early stages, but was highly up-regulated when the tumors are formed. Using flow cytometry, we found that the numbers of CD133 but not CD44 were increased at the very early phases of carcinogenesis (ACF), however, when tumors are formed, CD44 cells but not CD133 numbers were highly increased, both which could be putative stem cells with the highest stemness feature driving the carcinogenesis process. This indicates that their role during carcinogenesis is depending on the genetic and phenotypic characteristics of the phase of tumorigenesis in the colonic epithelial cell. The data have also shown that the protective effect of celecoxib on these specific markers and populations of CSCs and on other processes such as apoptosis and cellular proliferation targeted by these drugs may vary depending on the genetic and phenotypic stages of carcinogenesis. Thus understanding this differential role of CSCs during different phases of carcinogenesis could be useful for its targeted therapy.

\section{Acknowledgements}

This work was supported by a Grant-in Aid by the Egyptian Science and Technology Development Fund for basic and applied research (STDF; project ID: 7974). The authors wish to thank the responsible of the animal facility of the Zoology Department, Faculty of Science and the staff members of the Central Laboratory of Tanta University for their sincere technical assistance.

\section{References}

Al-Hajj M, Wicha MS, Benito-Hernandez A, Morrison SJ, Clarke MF (2003). Prospective identification of tumorigenic breast cancer cells. Proc Natl Acad Sci U S A, 100,3983-8.

Al-Henhena N, Khalifa SA, Ying RP, et al (2015). Evaluation of chemopreventive potential of Strobilanthes crispus against colon cancer formation in vitro and in vivo. BMC Complement Altern Med, 15, 419.

Aruffo A, Stamenkovic I, Melnick M, et al (1990). CD44 is the principal cell surface receptor for hyaluronate. Cell, 61, 1303-13.

Barker N, Ridgway RA, van Es JH, et al (2009). Crypt stem cells as the cells of origin of intestinal cancer. Nature, 457, 608-12.

Basiji DA, Ortyn WE, Liang L, Venkatachalam V, Morrissey P (2007). Cellular image analysis and imaging by flow cytometry. Clin Lab Med, 27, 653-70.

Boman BM, Walters R, Fields JZ, et al (2004). Colonic crypt changes during adenoma development in familial adenomatous polyposis: immunohistochemical evidence for expansion of the crypt base cell population. Am J Pathol, 165, 1489-98.

Boman BM, Fields JZ, Cavanaugh KL, et al (2008a). How dysregulated colonic crypt dynamics cause stem cell overpopulation and initiate colon cancer. Cancer Res, 6 , 3304-13.

Boman BM, Huang E (2008b). Human colon cancer stem cells: a new paradigm in gastrointestinal oncology. J Clin Oncol, 26, 2828-38.

Bonnet D (2005). Cancer stem cells. AMLs show the way. Biochem Soc Trans, 33, 1531-3.

Cheng C, Sharp PA (2006). Regulation of CD44 alternative splicing by SRm160 and its potential role in tumor cell invasion. Mol Cell Biol, 26, 362-70.

Corpet DE, Tache S (2002). Most effective colon cancer chemopreventive agents in rats: A systematic review of aberrant crypt foci and tumor data, ranked by potency. Nutr Cancer, 43, 1-21.

Costabile V, Duraturo F, Delrio P et al (2015). Lithium chloride induces mesenchymal to epithelial reverting transition in 
primary colon cancer cell cultures. Int J Oncol, 46, 1913-23.

Dalerba P, Dylla SJ, Park IK, et al (2007). Phenotypic characterization of human colorectal cancer stem cells. PNAS, 104, 10158-163.

Dean PN, Jett JH (1974). Mathematical analysis of DNA distributions derived from microfluorometry. J Cell Biol, 40, 523-7.

Dylla SJ, Beviglia L, Park IK, et al (2008). Colorectal cancer stem cells are enriched in xenogeneic tumors following chemotherapy. PLOS ONE, 3, 2428.

Elzagheid A, Algars A, Bendardaf R, et al (2006). E-cadherin expression pattern in primary colorectal carcinomas and their metastases reflects disease outcome. World J Gastroenterol, 12, 4304-9.

Fearon ER, Vogelstein B (1990). A genetic model for colorectal tumorigenesis. Cell, 61, 759-67.

Fernandes CR, Turatti A, Gouvea DR, et al (2011). The protective role of Lychnophora ericoides Mart. (Brazilian arnica) in 1,2-dimethylhydrazine-induced experimental colon carcinogenesis. Nutr Cancer, 63, 593-9.

Fhu CW, Graham AM, Yap CT, et al (2014). Reed-Sternberg cell-derived lymphotoxin- $\alpha$ activates endothelial cells to enhance T-cell recruitment in classical Hodgkin lymphoma. Blood, 124, 2973-82.

Hsu SM, Raine L, Fanger H, (1981). Use of avidin-biotinperoxidase complex $(\mathrm{ABC})$ in immunoperoxidase techniques: a comparison between $\mathrm{ABC}$ and unlabeled antibody (PAP) procedures. J Histochem. Cytochem, 29, 577-580.

Huang EH, Hynes MJ, Zhang T, et al (2009). Aldehyde Dehydrogenase 1 is a marker for normal and malignant human colonic stem cells and tracks stem cell overpopulation during colon tumorigenesis. Cancer Res, 69, 3382-9.

Kim JY, Alam F, Chung SW (2014). Combinational chemoprevention effect of Celecoxib and an oral antiangiogenic LHD4 on colorectal carcinogenesis in mice. Anticancer Drugs, 25, 1061-71.

Kochi T, Shimizu M, Shirakami Y, et al (2015). Utility of Apcmutant rats with a colitis-associated colon carcinogenesis model for chemoprevention studies. Eur J Cancer Prev, 24, 180-7.

Kopp R, Fichter M, Schalhorn G, Danescu J, Classen S (2009). Frequent expression of the high molecular, 673-bp CD44v3, v8-10 variant in colorectal adenomas and carcinomas. Int $J$ Mol Med, 24, 677-83.

Kuniyasu H, Ohmori H, Sasaki T (2003). Production of interleukin 15 by human colon cancer cells is associated with induction of mucosal hyperplasia, angiogenesis, and metastasis. Clin Cancer Res, 9, 4802-10.

Lei Du, Hongyi Wang, Leya He, et al (2008). CD44 is of functional importance for colorectal cancer stem cells. Clin Cancer Res, 6751.

Levi E, Mohammad R, Kodali U (2004). EGF-receptor related protein causes cell cycle arrest and induces apoptosis of colon cancer cells in vitro and in vivo. Anticancer Res, 24(5A), 2885-91.

Liu R, Shen Y, Nan K, et al (2015). Association Between Expression Of Cancer Stem Cell Markers And Poor Differentiation Of Hepatocellular Carcinoma: A MetaAnalysis (Prisma). Med (Baltimore), 94, 1306.

Losi L, Roncucci L, Digregorio C, et al (1996). K-ras and P53 mutation in human colorectal aberrant crypt foci. J Pathol, 128, 259-63.

Lynch PM, Burke CA, Phillips R, et al (2015). An international randomised trial of Celecoxib versus Celecoxib plus difluoromethylornithine in patients with familial adenomatous polyposis. Gut, 307235 .

Malmstrom PU, Busch C, Norlen BJ, et al (1988). Expression of $\mathrm{ABH}$ blood group isoantigen as a prognostic factor in transitional cell bladder carcinoma. Scand J Urol Nephrol, 22, 265-70.

Marcato P, Dean CA, Giacomantonio CA, Lee PW (2011). Aldehyde dehydrogenase: its role as a cancer stem cell marker comes down to the specific isoform. Cell Cycle, 10, 1378-84

Munz M, Baeuerle PA, Gires O (2009). The emerging role of epcam in cancer and stem cell signaling. Cancer Res, $\mathbf{6 9}$, 5627-9.

Nautiyal J, Du J, Yu Y, (2012). EGFR regulation of colon cancer stem-like cells during aging and in response to the colonic carcinogen dimethylhydrazine. Am J Physiol Gastrointest Liver Physiol, 302, 655-63.

O'Brien CA, Pollett A, Gallinger S, Dick JE (2007). A human colon cancer cell capable of initiating tumour growth in immunodeficient mice. Nature, 445, 106-10.

O'Leary KE, Cruess DG, Pleau D, et al (2011). Sex differences in associations between psychosocial factors and aberrant crypt foci among patients at risk for colon cancer. Gend Med, 8, 165-71

Osta WA, Chen Y, Mikhitarian K (2004). EpCAM is overexpressed in breast cancer and is a potential target for breast cancer gene therapy. Cancer Res, 64, 5818-24.

Ottinger S, Klöppel A, Rausch V, Liu L, Kallifatidis G, Gross W, Gebhard MM, Brümmer F, Herr I (2012). Targeting of pancreatic and prostate cancer stem cell characteristics by Crambe crambe marine sponge extract. Int J Cancer, $\mathbf{1 3 0}$, 1671-81.

Parafiniewicz B, Pendzich J, Gruchlik A (2012). Impact of celecoxib on soluble intercellular adhesion molecule-1 and soluble E-Cadherin concentrations in human colon cancer cell line cultures exposed to phytic acid and TNF- $\alpha$. Acta Poloniae Pharmaceutica Drug Res, 69, 1283-90.

Patlolla JM, Zhang Y, Li Q, et al (2012). Anti-carcinogenic properties of omeprazole against human colon cancer cells and azoxymethane-induced colonic aberrant crypt foci formation in rats. Int J Oncol, 40, 170-5.

Patriarca C, Macchi RM, Marschner AK, et al (2012). E-cadherin expression pattern in primary colorectal carcinomas and their metastases reflects disease outcome. Cancer Treat Rev, 38, 68-75.

Pommergaard HC, Burcharth J, Rosenberg J, et al (2015). Aspirin, Calcitriol, and Calcium Do Not Prevent Adenoma Recurrence in a Randomized Controlled Trial. Gastroenterol, 6-5085(15)01354-2.

Rao CV, Steele VE, Swamy MV, (2009). Inhibition of azoxymethane-induced colorectal cancer by CP-31398, a TP53 modulator, alone or in combination with low doses of celecoxib in male F344 rats. Cancer Res, 69, 8175-82.

Ricci-Vitiani L, Lombardi DG, Pilozzi E, Biffoni M, Todaro M, et al (2007). Identification and expansion of human coloncancer-initiating cells. Nature, 445, 111-5.

Roncucci L, Medline A, Bruce WR (1991). Classification of aberrant crypt foci and microadenomas in human colon. Cancer Epidemiol Biomarkers Prev, 1, 57-60.

Saini MK, Sanyal SN (2012). PTEN regulates apoptotic cell death through PI3-K/Akt/GSK3 $\beta$ signaling pathway in $\mathrm{DMH}$ induced early colon carcinogenesis in rat. Exp Mol Pathol, 93, 135-46.

Santisteban M, Reiman JM, Asiedu MK, et al, (2009). Immuneinduced epithelial to mesenchymal transition in vivo generates breast cancer stem cells. Cancer Res, 69, 2887-95.

Shen J, Wanibuchi H, Salim EI, et al (2003). Induction of glutathione S-transferase placental form-positive foci in liver and epithelial hyperplasia in urinary bladder, but no tumor development in male Fischer 344 rats treated with 

monomethylarsonic acid for 104 weeks. Toxicol and Applied Pharmacol, 193, 335-45.

Skidan I, Steiniger SC. (2014). In vivo models for cancer stem cell research: a practical guide for frequently used animal models and available biomarkers. J Physiol Pharmacol, $\mathbf{6 5}, 157-69$.

Steinbach G, Lynch PM, Phillips RK, et al (2000). The effect of celecoxib,a cyclooxygenase-2 inhibitor, in familial adenomatous polyposis. N Engl J Med, 342, 1946-52.

Tagde A, Singh H, Kang MH, Reynolds CP (2014). The glutathione synthesis inhibitor buthionine sulfoximine synergistically enhanced melphalan activity against preclinical models of multiple myeloma. Blood Cancer $J$, $4,229$.

Tang ZC, Shivapurkar N, Frost A, et al (1996). The effect of dietary fat on the promotion of mammary and colon cancer in a dual organ rat carcinogenesis model. Nutr Cancer, 25, 151-9.

Traganos F, Darzynkiewicz Z, Sharpless T, et al (1977). Simultaneous staining of ribonucleic and deoxyribonucleic acids in unfixed cells using acridine orange in a flow cytofluorometric system. J Histochem Cytochem, 25, 46-56.

van der Gun BT, Melchers LJ, Ruiters MH, et al (2010). EpCAM in carcinogenesis: the good, the bad or the ugly. Carcinogenesis, 11, 1913-21.

Tutlewska K, Lubinski J, Kurzawski G (2013). Hered. Germline deletions in the EPCAM gene as a cause of Lynch syndrome - literature review. Cancer Clin Pract, 11, 9.

van de Wetering M, Sancho E, Verweij C, et al (2002). The beta-catenin/TCF-4 complex imposes a crypt progenitor phenotype on colorectal cancer cells. Cell, 111, 241-50.

Wang L, Chen F, Zhang Z, Chen G, Luo J, Shi X (2012). Cancer stem cells in the mechanism of metal carcinogenesis. $J$ Environ Pathol Toxicol Oncol, 31, 245-63.

Went PT, Lugli A, Meier S (2004). Frequent EpCam protein expression in human carcinomas. Hum Pathol, 35, 122-8.

Yamamoto H, Imai K (2015). Microsatellite instability: an update, Arch Toxicol, 89, 899-921.

Zhu L, Gibson P, Currle DS, et al (2009). Prominin 1 marks intestinal stem cells that are susceptible to neoplastictransformation. Nature, 457, 603-8. 